\title{
CONFECÇÃo DE UM PERFURADOR DE LAMÍNULAS DE VIDRO POR CORROSÃo ÁCIDA
}

\section{Heron Dominguez Torres da Silva e Claudimir Lucio do Lago*}

Departamento de Química Fundamental, Instituto de Química, Universidade de São Paulo, Av. Prof. Lineu Prestes, 748, 05508-900 São Paulo - SP

Recebido em 9/4/02; aceito em 14/6/02

\begin{abstract}
A GLASS PLATE DRILLER BY ACID CORROSION. A simple device for glass plate drilling, which is an important step in microfabrication procedures, is described. A reservoir of concentrated hydrofluoric acid with a hole in its bottom is affixed against the glass plate. Leakage is prevented by using a neoprene O-ring. A plastic pipet tip inserted in the reservoir, close to the corrosion region, provides forced convection by pressure variations inside it. A device to make 5 simultaneous holes in a plate is also presented. For a $140 \mu \mathrm{m}$ thickness alkaline glass lamina and 1/8" O-ring, 5 holes are drilled in $20 \mathrm{~min}$.
\end{abstract}

Keywords: microfabrication; micro total analysis system; drilling; glass plate.

\section{INTRODUÇÃO}

Dentre as tendências atuais da química analítica, a dos microsistemas de análise total ("micro total analysis system" - $\mu$ TAS) é, sem dúvida, a que apresenta as mais diversas possibilidades ${ }^{1-8}$. De sistemas de separação baseados em eletroforese capilar e cromatografia a implementações de sistemas de análise por injeção em fluxo em micro-escala, aplicações em número expressivo foram e continuam sendo apresentadas.

Ao contrário do que alguns imaginam, não é a simples miniaturização o que desperta tanto interesse, mas as possibilidades de aumento de eficiência e o uso de novos princípios que surgem com a redução de escala.

Embora muito ativa em nível internacional, a área ainda conta com iniciativas modestas no Brasil. Uma das causas aparentes para esta defasagem é a crença de que sofisticadas técnicas de microfabricação, realizadas em ambientes limpos, são sempre necessárias para a construção dos dispositivos. A literatura possui diversos exemplos de aproximações simples e que resultam em dispositivos úteis ${ }^{9-13}$. No sentido de sugerir alternativas úteis à micro-fabricação, o objetivo desta nota é introduzir uma simples técnica de perfuração de lamínulas de vidro - etapa presente nos processos de fabricação de dispositivos micro-fluídicos - que pode servir à implementação de diversos dispositivos $\mu$ TAS.

Uma das técnicas mais bem estabelecidas para fabricação de dispositivos micro-fluídicos é a vidro-vidro ${ }^{14-18}$, isto é, os micro-canais são formados por corrosão de uma base de vidro plano e uma segunda placa de vidro é soldada posteriormente sobre esta. O acesso aos canais pode ser feito pela lateral da estrutura de vidro - desde que os canais atinjam a borda da mesma. Porém, a aproximação mais comum é a perfuração de uma das placas de vidro. Em muitos casos, estes furos são também utilizados como reservatórios de solução.

A estratégia utilizada por Jacobson e colaboradores ${ }^{17,18}$ na fase inicial de seu trabalho foi a confecção de canais em lâminas de vidro de microscópio por técnicas fotolitográficas e posterior recobrimento com a correspondente lamínula. Esta parece ser uma das melhores estratégias para aqueles que estão em estágio semelhante. Porém, uma das deficiências encontradas era a necessidade de se fazer o

*e-mail: claudemi@iq.usp.br acesso aos canais nas bordas da lamínula, já que esta era utilizada integralmente (sem furos).

Nesta nota técnica, um procedimento simples e versátil para perfuração de lamínulas é descrito. Ao invés de utilizar perfurador ultrasônico ou broca diamantada, ambos de custo relativamente elevado, a perfuração é conseguida por corrosão com ácido fluorídrico aplicado de forma localizada.

\section{PARTE EXPERIMENTAL}

A fórmula básica consiste em utilizar um dispositivo que contenha um reservatório para o ácido fluorídrico e que pressione o fundo deste reservatório contra a lamínula, utilizando um anel de vedação. A Figura 1 mostra em detalhe como isso é conseguido. Embora seja possível utilizar um reservatório de grandes dimensões, o que garante disponibilidade de ácido fluorídrico, a corrosão é lenta porque a renovação da solução na região próxima ao vidro se dá basicamente por difusão.

Para aumentar a velocidade de corrosão, um sistema que força a convecção nesta região foi acrescentado. Uma ponteira plástica de pipetador automático é posicionada a uma distância muito pequena da superfície (Figura 1) e movimentos de sucção e expulsão de líquido do seu interior garantem a convecção necessária.

Uma vez que ácido fluorídrico concentrado é utilizado, deve-se tomar extremo cuidado com o seu manuseio, assim como escolher materiais adequados para este fim. O procedimento descrito a seguir

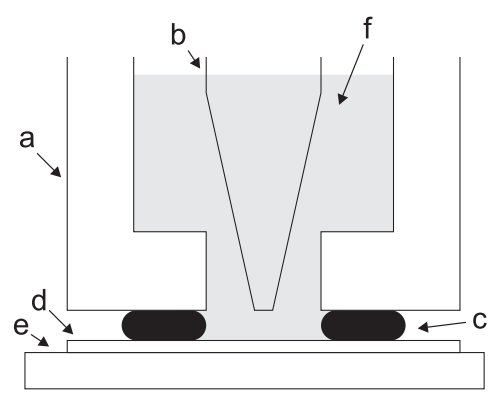

Figura 1. Esquema geral do dispositivo para corrosão de vidro: (a) reservatório de solução corrosiva; (b) ponteira plástica; (c) anel O-ring; (d) lamínula de vidro; (e) suporte plástico; (f) solução corrosiva 
mostra como um dispositivo para corrosão pode ser implementado. No entanto, é possível adaptá-lo facilmente para outras configurações.

A Figura 2 mostra uma visão das partes necessárias para promover a corrosão de cinco orifícios simultaneamente sobre a mesma lamínula, o que mostra que, além de simples e versátil, a estratégia aumenta a velocidade de produção quando comparada à furação individual.

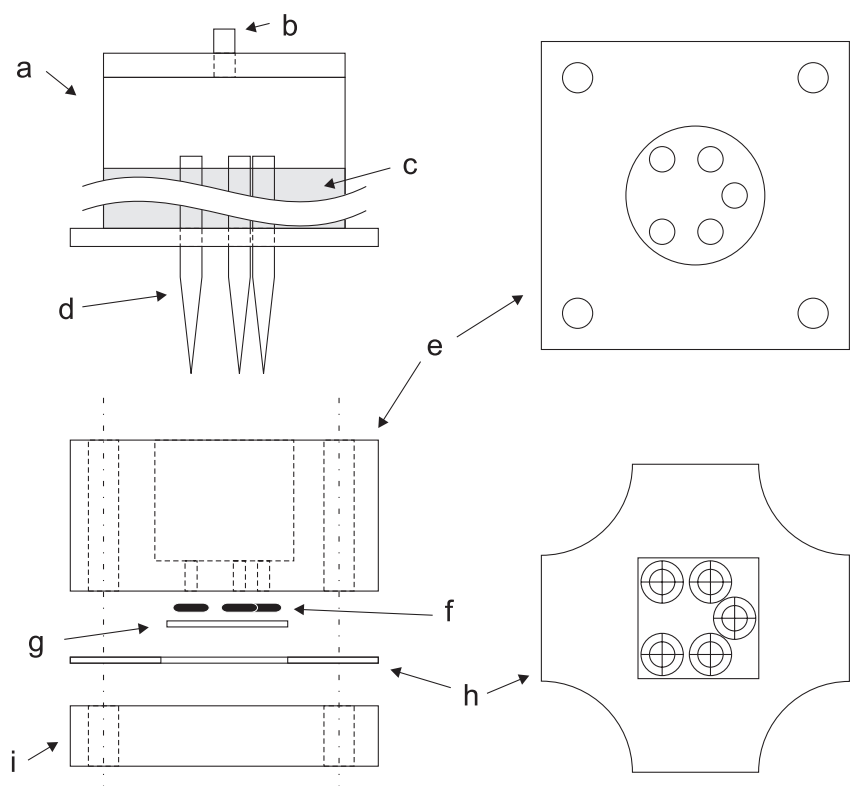

Figura 2. Visão explodida do dispositivo para corrosão de cinco orifícios em lamínula de $20 \times 20$ mm: (a) agitador pneumático de solução; (b) entrada e saída de ar; (c) resina de poliéster para imobilização das ponteiras; (d) ponteiras; (e) bloco reservatório (vista lateral e superior); $(f)$ anéis de vedação; ( $g$ ) lamínula de vidro; (h) filme de poliéster com a matriz de furação impressa (vista lateral e superior); (i) base em acrílico

O primeiro passo consiste na definição da matriz de furação. Isto foi realizado, em nosso caso, utilizando-se o programa CorelDRAW 7 (Corel, Versão 7.468). Uma vez impressa, a matriz orientou a furação no fundo do bloco reservatório (Figura 2) confeccionado em PVC. Uma cópia da matriz foi impressa em filme de poliéster de transparência a laser (3M, modelo 3300), a qual foi recortada e posicionada sobre a base de acrílico de $10 \mathrm{~mm}$ de espessura. Este filme de poliéster auxilia no posicionamento da lamínula de vidro alcalino $\mathrm{n}^{\circ} 1 \mathrm{de}$ 20 x $20 \mathrm{~mm}$ e $140 \mu \mathrm{m}$ de espessura (Marienfeld, Alemanha) e anéis O-ring de neoprene (borracha nitrílica com diâmetro interno de 1/8", diâmetro externo de 1/4") sobre a base. Após este posicionamento, o bloco reservatório é firmemente fixado com o uso de quatro parafusos de $1 / 8$ " de diâmetro.

Um conjunto de cinco ponteiras de polipropileno de $1 \mathrm{~mL}$ foram imobilizadas com resina de poliéster isoftálica Centerpol 742 (Fiber Center, Santo André - SP) sobre uma placa de acrílico de $5 \mathrm{~mm}$ de espessura, após perfuração da mesma. Esta é uma etapa que exige um cuidado especial, pois a extremidade da ponteira deve ser centralizada no furo e atingir o mesmo nível do fundo do bloco reservatório. Desta forma, após a fixação contra os anéis de vedação, as ponteiras ficam a aproximadamente $260 \mu \mathrm{m}$ da superfície do vidro. Este cuidado no posicionamento é importante para garantir uma taxa de corrosão uniforme em todos os orifícios. A contenção da resina de poliéster foi feita por um tubo de acrílico de $350 \mathrm{~mm}$ de diâmetro interno, podendo ser substituído por PVC. Este tubo foi fechado na parte superior, servindo também como câmara onde o ar é comprimido e expandido para forçar a movimentação do ácido no interior das ponteiras. A compressão e descompressão foram conseguidas pelo uso de uma seringa de $1 \mathrm{~mL}$ conectada à câmara por tubo plástico.

O conjunto utilizado para forçar a convecção requer a utilização de diferentes materiais e deve-se destacar a escolha destes. A idéia durante a convecção forçada é aspirar a solução de corrosão até preencher parcialmente a ponteira, evitando o transbordamento do líquido no interior da câmara. Desta forma, a parte crítica em termos de exposição à corrosão é a própria ponteira, que é confeccionada em material resistente ao ácido. Os materiais descritos têm apresentado boa resistência à exposição dos vapores corrosivos. Embora ocorra antes de deterioração aparente, os anéis de vedação utilizados têm sido substituídos a cada 10 operações. Deve salientar-se que nenhuma parte deve ser confeccionada em vidro.

$\mathrm{O}$ procedimento que tem sido utilizado para a corrosão de lamínulas de vidro alcalino de $140 \mu \mathrm{m}$ de espessura é o seguinte. Após a fixação da lamínula como descrito anteriormente, o bloco reservatório é preenchido com ácido fluorídrico 40 \% (v/v) (Merck, $\mathrm{RJ})$. O conjunto para convecção forçada é posicionado sobre o bloco reservatório. Inicialmente são realizados dez movimentos com a seringa, deslocando aproximadamente $1 \mathrm{~mL}$ de ar em seu interior em cada um deles. Este procedimento evita que bolhas de ar sejam alojadas nos orifícios, o que diminuiria a disponibilidade de solução corrosiva e levaria a taxas de corrosão não uniformes em cada um deles. Após este estágio inicial, a solução é movimentada pelo deslocamento de $1 \mathrm{~mL}$ na seringa a cada $5 \mathrm{~min}$. Em nosso caso, o tempo ótimo de corrosão tem sido de $20 \mathrm{~min}$. Após este período, a solução contida no reservatório é vertida sobre $100 \mathrm{~mL}$ de solução aquosa $20 \%$ de $\mathrm{NaOH}$ (volume suficiente para cinco operações com segurança). Este procedimento, que deve ser feito com cuidado, gera um resíduo mais apropriado para descarte. O reservatório é lavado várias vezes com água destilada antes que o conjunto seja desmontado. Após sua remoção, a lamínula deve ser lavada cuidadosamente para garantir que nenhum resíduo ácido dê continuidade ao processo corrosivo. $\mathrm{O}$ mesmo cuidado de limpeza deve ser tomado com as partes do dispositivo construído.

A Figura 3 mostra como o processo de corrosão se processa. Devido à isotropia, a lamínula não é corroída somente no sentido da espessura. A corrosão ocorre também sob o anel de vedação numa extensão que, devido à maior estagnação da solução neste local, é um pouco inferior àquela que ocorre no sentido da espessura da lamínula. Assim, após a perfuração da lamínula, o processo deve ser imediatamente interrompido.

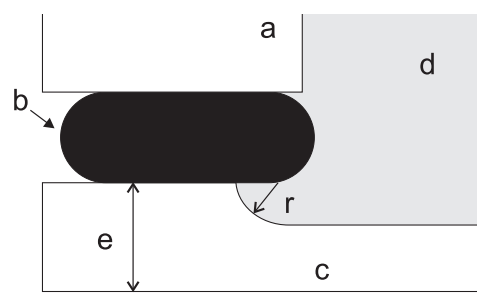

Figura 3. Detalhe da região próxima ao anel de vedação durante a corrosão: (a) bloco reservatório; (b) anel de vedação; (c) lamínula de vidro; (d) solução corrosiva. A corrosão ocorre numa extensão aproximadamente uniforme (r) e deve ser interrompida quando esta atinge o valor da espessura (e) da lamínula 


\section{RESULTADOS E DISCUSSÃO}

O aspecto do orifício é mostrado na Figura 4. Quando o tempo ótimo é utilizado, o orifício formado possui o diâmetro médio de 3,2 mm. A Figura $4 \mathrm{~b}$ mostra o aspecto do orifício formado quando a lamínula é exposta à solução corrosiva por um período adicional de cinco minutos. Nota-se o aumento do diâmetro e a formação de bordas irregulares.
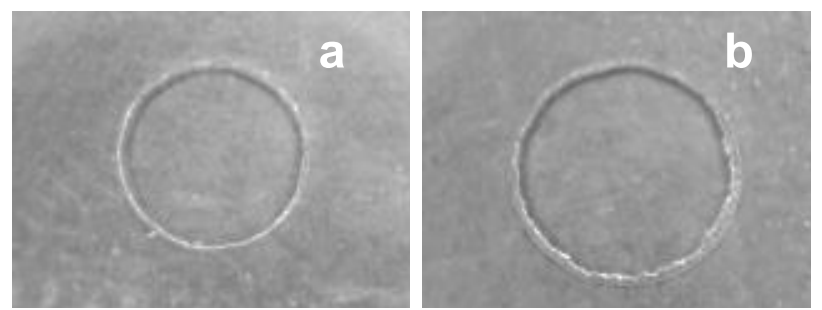

Figura 4. Fotografias do orifício gerado em lamínula de 140 um de espessura quando o tempo utilizado é o ótimo (a) e quando este é excedido em 5 min (b)

Com a utilização de tempos muito superiores ao ótimo, o diâmetro do furo pode aumentar a ponto do anel O-ring não conseguir conter a solução corrosiva. Com isso, não apenas a peça gerada é perdida como também ocorre um derramamento da solução nas imediações. Assim, mesmo tendo sido estabelecido o tempo ótimo, é conveniente realizar o processo em uma bandeja plástica para evitar acidentes.

Ao invés de ácido fluorídrico concentrado, pode-se utilizar uma solução tampão à base de ácido fluorídrico e fluoreto de amônio (6 volumes de $\mathrm{NH}_{4} \mathrm{~F} 400 \mathrm{~g} / \mathrm{L}+2$ volumes de $\mathrm{HF} 40 \%$ (v/v)). Devido ao controle do $\mathrm{pH}$, esta solução permite obter uma taxa de corrosão mais uniforme durante sua vida útil, o que facilita seu reaproveitamento. No entanto, o tempo de corrosão aumenta significativamente (55 min em nosso caso).

O processo pode ser facilmente adaptado para corrosão de outras peças de vidro - inclusive com espessuras maiores -, mas devese tomar alguns cuidados. Uma vez que o processo de corrosão é isotrópico, a espessura do vidro deve ser sempre menor que a espessura do anel de vedação. Caso contrário, ocorrerá o derrame de solução antes que o furo seja completado.

\section{CONCLUSÃO}

Considerando as perspectivas, cada vez mais acentuadas, de desenvolvimento da microfabricação para química analítica e o crescente interesse de grupos de pesquisa nesta área, concluímos que um sistema simples e de baixo custo para corrosão em vidro será de grande valia, principalmente para confecção rápida de protótipos.

\section{AGRADECIMENTOS}

Os autores agradecem à Fundação de Amparo à Pesquisa do Estado de São Paulo (FAPESP) e ao Conselho Nacional de Pesquisa e Desenvolvimento Científico e Tecnológico (CNPq) pelo apoio financeiro.

\section{REFERÊNCIAS}

1. Manz, A.; Graber, N.; Widmer, H. M.; Sens. Actuators, B 1990, 1, 244.

2. Manz, A.; Fettinger, J. C.; Veroporte, E.; Ludi, H.; Widmer, H. M.; Harrison, D. J.; Trends Anal. Chem. 1991, 10, 144.

3. Harrison, D. J.; Flury, K.; Seiler, K.; Fan, Z.; Effenhauser, C. S.; Manz, A.; Science 1993, 261, 895.

4. Manz, A.; Harrison, D. J.; Verpoorte, E.; Widmer, H. M.; Adv. Chromatogr. 1993, 33, 1 .

5. Blankenstein, G.; Larsen, U. D.; Biosens. Bioelectron. 1998, 13, 427.

6. Manz, A.; Chimia 1996, 50, 140.

7. Kutter, J.; Trends Anal. Chem. 2000, 19, 352.

8. Figeys, D.; Ocata, M. D. S.; Pinto, D.; Anal. Chem. 2000, 72, 350.

9. Fintschenko, Y.; Berg, A.; J. Chromatogr. 1998, 891, 3.

10. McCreedy, T.; Trends Anal. Chem. 2000, 19, 396.

11. Soper, S. A.; Ford, S. M.; Qi, S.; McCarley, R. L.; Kelly, K.; Murphy, M. C.; Anal. Chem. 2000, 72, 643A.

12. Martynova, L.; Locascio, L. E.; Galtan, M.; Kramer, G. W.; Christensen, R. G.; MacCrehan, W. A.; Anal. Chem. 1997, 69, 4783.

13. Silva, H. D. T.; Dissertação de Mestrado, Universidade de São Paulo, Brasil, 2001.

14. Harrison, J. D.; Manz, A.; Fan, Z.; Ludi, H.; Widmer, H. M.; Anal. Chem. 1992, 64, 1926

15. Effenhauser, S. C.; Manz, A.; Widmer, H. M.; Anal. Chem. 1993, 65, 2637.

16. Seiler, K.; Harrison, D. J.; Manz, A.; Anal. Chem. 1993, 65, 1481.

17. Jacobson, S. C.; Hergenroder, R.; Koutny, L. B.; Ramsey, M. J.; Anal. Chem. 1994, 66, 1114.

18. Jacobson, S. C.; Hergenroder, R.; Koutny, L. B.; Ramsey, M. J.; Anal. Chem. 1994, 66, 2369. 